\title{
Interim Statistical Report
}

National Cancer Institute

\section{Source}

National Cancer Institute. Interim Statistical Report. NCI Thesaurus. Code C115585.

Records summarizing information and data related to the statistics of an interim analysis from a clinical trial. 